\title{
Clinical and Prognostic Aspects of Obstetric Acute Renal Failure in the Nephrology and Hemodialysis Department of the Point G Teaching Hospital in Mali
}

Fofana Aboubacar Sidiki $^{1 *}$, Yattara Hamadoun ${ }^{1}$, Sy Seydou${ }^{1}$, Samaké Magara ${ }^{2}$, Coulibaly Moctar ${ }^{3}$, Coulibaly Sah dit Baba $^{1}$, Diallo Djénéba ${ }^{1}$, Sima Mamadou ${ }^{4}$, Sidibé Modi ${ }^{1}$, Kodio Atabieme ${ }^{1}$, Touré Alkaya ${ }^{1}$, Coulibaly Nouhoum ${ }^{1}$, Tangara Moustapha ${ }^{1}$, Fongoro Saharé ${ }^{1}$

${ }^{1}$ Departement of Nephrology and Hemodialysis at the Point G teaching Hospital in Mali

${ }^{2}$ Department of Medicine and Medical Specialties, Regional Hospital, Kayes/Mali

${ }^{3}$ Nephrology Unit of the Mali GAVARDO Hospital in Bamako, Mali

${ }^{4}$ Department of Gynaeco-Obstetrics, Point G Teaching Hospital in Mali

DOI: $10.36347 /$ sasjm.2020.v06i06.001

| Received: 07.04.2020 | Accepted: 14.04.2020 | Published: 06.06.2020

*Corresponding author: Aboubacar Sidiki Fofana

Abstract

Original Research Article

Introduction: Acute kidney injury (AKI) remains a serious and frequent complication in developing countries. Objective: To evaluate the clinical and evolutionary profile of patients hospitalized for acute obstetric renal failure in the nephrology department of the Point G teaching hospital in Mali. Patients and methods: This was a prospective and descriptive study from June 1, 2015 to June 1, 2019. Results: The prevalence of obstetrical AKI in the nephrology department of the Point $G$ teaching hospital was $2.08 \%$. The majority of AKI occurred postpartum 61 cases versus 2 cases during pregnancy after the 20th week of amenorrhea. The mean age of the patients was $27.31 \pm 5.49$ years. Blood pressure was normal in $30.2 \%$ of participants. According to the WHO classification of hypertensive patients, hypertension grade 2 was found in $36.5 \%$ of cases followed by grade 3 and $1(17.5 \%$ and $15.9 \%)$. The average blood pressure was $150.39 / 98.68 \mathrm{mmHg}$. The haemogram objectified severe anaemia in thirty-five patients. The causes of AKI were severe preeclampsia (55.5\%), postpartum hemorrhage (36.5\%), post-clandestine abortion sepsis $(3.2 \%)$, severe Palsmodium falciparum malaria (1.6\%), severe superimposed preeclampsia (1.6\%) and hemolytic uremic syndrome (1.6\%). Forty-six patients were dialysed, i.e. $73 \%$. During their follow-up, total recovery of renal function was observed in $67.9 \%$ (31 cases) versus 1 case of partial recovery, 4 patients progressed to end-stage chronic renal failure, 7 cases of death were observed and 3 cases of discontinuation of follow-up. Among the non-dialysis patients, recovery of ad-integrum renal function was observed in 16 patients and 1 case of death. Maternal and perinatal mortality was $12.69 \%$ and $41.2 \%$ of cases. Conclusion: Obstetric AKI remains common in Africa. Screening for renal impairment during pregnancy should be routine. We insist on primary prevention of obstetrical complications, decentralization of dialysis centers, close collaboration between nephrologist and obstetrician in order to significantly reduce this non-negligible morbi-mortality.

Keywords: Acute renal failure, obstetrical, prognostic, Mali.

Copyright @ 2020: This is an open-access article distributed under the terms of the Creative Commons Attribution license which permits unrestricted use, distribution, and reproduction in any medium for non-commercial use (NonCommercial, or CC-BY-NC) provided the original author and source are credited.

\section{INTRODUCTION}

Obstetric acute renal failure remains a serious and frequent complication responsible for high maternal-fetal morbidity and mortality in developing countries, whereas it has become rare in developed countries [1]. AKI in pregnancy encompasses all causes of impaired renal function between the beginning and end of pregnancy. Obstetric AKI includes gestational AKI and postpartum AKI [2].
In recent decades, gestational $\mathrm{AKF}$ has been most common in the setting of preeclampsia or severe eclampsia, and postpartum AKF is mainly the result of massive bleeding and bleeding disorders [3]. Other nonspecific kidney diseases (systemic diseases, pyelonephritis gravidarum) coincide with pregnancy and may complicate or be complicated by pregnancy [4].

In developed countries the incidence of obstetric AKI has been declining in recent decades. In France, its incidence fell from 1 per 3000 pregnancies 
before the 1970 s to 1 per 20,000 pregnancies in 2001 , i.e. about $2-3 \%$ of acute renal failure compared with 20 $40 \%$ in the 1950 s to 1960 s [5]. On the other hand, in developing countries it is still a significant cause of maternal mortality. In Mauritania, the prevalence of post-partum ARI in the national hospital of Nouakchott is $4.61 \%$ with a mortality rate of $13.23 \%$ [6].

In Mali a retrospective study carried out in the Nephrology Department of the Point G University Hospital over a period from 1 January 2010 to 31 December 2012 revealed 28 cases of obstetric ARI with total recovery of renal function in $39 \%$ of cases and a mortality rate of $21.42 \%$ [7].

The aim of this work was to evaluate the prevalence, clinical and evolutionary profile of patients hospitalized for acute obstetric renal failure in the nephrology department of the University Teaching Hospital of Point G.

\section{PATIENTS AND METHODS}

1. Setting and location of the study: The Point G teaching hospital in Mali is a level 3 reference centre which houses the only nephrology and haemodialysis service. This service receives patients with kidney diseases from all regions of Mali, the district of Bamako and some neighboring countries including Guinea Conakry and Ivory Coast.

2. Type and period of study: This was a prospective and descriptive study with a duration of 4 years from 1 June 2015 to 31 June 2019.

\section{Criteria for Inclusion}

- Patients hospitalized for acute obstetrical renal failure beyond the 20th week of amenorrhea or within the first three months postpartum with a complete record (clinical examination results, additional examinations, reports of interventions and treatment protocols implemented).

- Absence of other non-obstetrical situations that may cause or promote ARF, namely the use of nephrotoxic drugs (aminoglycosides) or injection of iodinated contrast media.

Non-inclusion Criteria: Not included in this study

- Patients with ARF before the 20th week of amenorrhea

- Patients hospitalized for chronic kidney disease decompensated by pregnancy

- Non-consenting patient

Definition Criteria Used

- Definition of AKI (Table-1).

Table-1: KDIGO (Kidney Disease Improving Global Outcome 2012) universal definition of acute renal failure [8]

\begin{tabular}{|l|l|l|}
\hline Stage AKI & Creatinine* & Diuresis \\
\hline 1 & $\begin{array}{l}\text { Increase }>26 \mu \mathrm{mol} / \mathrm{L}(3 \mathrm{mg} / \mathrm{L}) \text { in } 48 \text { hours } \\
\text { or }>50 \% \text { in } 7 \text { days }\end{array}$ & $<0.5 \mathrm{ml} / \mathrm{kg} / \mathrm{h}$ for $6-12 \mathrm{hrs}$ \\
\hline 2 & Creatinine x 2 & $<0.5 \mathrm{ml} / \mathrm{kg} / \mathrm{h} \geq 12 \mathrm{hrs}$ \\
\hline 3 & $\begin{array}{l}\text { Creatinine x } 3 \text { Or creatinine }>354 \mu \mathrm{mol} / \mathrm{L}(40 \mathrm{mg} / \mathrm{L}) \\
\text { in the absence of prior value or need for dialysis }\end{array}$ & $\begin{array}{l}<0.3 \mathrm{ml} / \mathrm{kg} / \mathrm{h} \geq 24 \mathrm{hours} \text { or } \\
\text { anuria } \geq 12 \mathrm{~h}\end{array}$ \\
\hline
\end{tabular}

* We used the creatinine criterion this study

- Oliguria is defined as diuresis less than 500 $\mathrm{ml} / 24 \mathrm{H}$, anuria as diuresis less than 100 $\mathrm{ml} / 24 \mathrm{H}$ and polyuria as diuresis greater than $2 \mathrm{ml} / \mathrm{Kg} / \mathrm{H}$.

- Pregnant hypertension (PH) is defined as a PAS $\geq 140 \mathrm{mmHg}$ and/or $\mathrm{PAD} \geq 90 \mathrm{mmHg}$ occurring after the 20 o week of amenorrhea and disappearing before the 6th week postpartum.

- Preeclampsia is defined as a combination of GHAT and proteinuria greater than $300 \mathrm{mg} / 24 \mathrm{H}$.

- Severe preeclampsia is preeclampsia associated with at least one of the following signs:

- $\quad$ Severe high blood pressure $(\mathrm{SBP} \geq 160 \mathrm{mmHg}$ and/or $\mathrm{DBP} \geq 110 \mathrm{mmHg}$ ).

- Renal impairment (oliguria $<500 \mathrm{ml} / 24 \mathrm{H}$, or creatinine $>135 \mu \mathrm{mol} / \mathrm{l}$ or proteinuria $>5 \mathrm{~g} / \mathrm{l})$.

- Acute pulmonary edema (APE) or persistent epigastric bar pain or HELLP syndrome.
- Neurological disorders (phosphene, headache, polycinetic osteotendinous reflexes) or eclampsia.

- Retroplacental hematoma (RPH) or fetal impact (growth retardation).

- The diagnosis of HELLP syndrome was defined by hepatic cytolysis (ASAT > 72 IU/l) and thrombocytopenia $(<100,000 / \mathrm{mm} 3)$.

- Eclampsia is a tonic-clonic convulsive seizure occurring in a hypertensive context of pregnancy.

\section{Parameters Studied}

Each patient in the series was given an individual survey form (after obtaining the consent of the patient or trusted person) which allowed us to collect the following data:

- Socio-demographic parameters namely: age, profession, socio-economic level (group I= senior state and/or private sector executives and import-export traders, group $\mathrm{II}=$ state 
agents and/or private sector employees and average traders, group III= workers, peasants, retail traders, and casual workers in towns, provinces).

- Gynaecological-obstetrical history: prenatal consultations, abortions, term of pregnancy (between 37-41 weeks), context of delivery, gestational age, parity.

- The clinical data sought are the medical history with types of hypertension, diabetes and oedema of the lower limbs. Symptoms studied were epigastric bar, thoracic and/or pelvic pain, headache, dizziness, tinnitus, phosphene, asthenia, nausea and vomiting.

- The general examination looked for hypertension, jaundice, edematous syndrome. The gynecological examination was done to report bleeding and/or pathological leukorrhea.

- Urinary strips were performed on the urine of each participant in the series.

- The standards used for the biological examinations were those of the various biological laboratories in Bamako.

- Kidney ultrasound was performed to measure the size of the kidneys and to look for dilatation of the pyelocalicial cavities.

- The emergency indications for haemodialysis retained in this study were hyperkalaemia (6.5 $<\mathrm{K}+\leq 7.5 \mathrm{mmol} / \mathrm{l})$, severe metabolic acidosis (< $12 \mathrm{mmol} / \mathrm{l})$ without corrective margin by bicarbonate infusion, acute pulmonary edema, uremic syndrome (encephalopathy, pericardial rubbing) and anuria in the absence of obstruction.

- If haemodialysis was indicated, the central catheter was inserted via the femoral route by the doctors on the ward. The haemodialysis sessions were close together (once a day) in the severe and anuric forms, but spaced every two to three days when the patient was stable without further visceral involvement and with a preserved diuresis. The dialysis catheter was removed once diuresis was resumed and creatinine levels were declining.

- Patients were followed as outpatients after their nephrological inpatient stay. The rhythm of follow-up was a weekly visit with monitoring of renal function.

- Data entry was done on EPI-DATA 3.1 software.

- The data were analysed on SPSS 21.0 French version, R 3.6.1 and Excel 2016. The writing was done on Word 2016.

The statistical comparison test was Pearson chi-square with Yates correction. A P value less than or equal to 0.05 was considered statistically significant.

\section{Ethicals Considerations}

Free and informed consent was obtained from each participant or her support person with strict adherence to the anonymity of the survey form.

\section{RESULTS}

From June 2015 to June 2019, the prevalence of obstetric ARI in the nephrology department Point G teaching hospital was $2.08 \%$, i.e. 63 cases out of 3019 hospitalisations. ARI occurred mainly in postpartum (61 cases) and more rarely during pregnancy (2 cases) after the 20th week of amenorrhoea.

The mean age of our patients was $27.31 \pm 5.49$ years, with extremes of 16 and 40 years. Patients aged between 26 and 30 years were the most numerous, i.e. $46 \%$ of cases (Table-2). The majority of patients were housewives $(87.3 \%)$ with a low socioeconomic level $(90.5 \%)$.

The reasons for hospitalization were renal failure in $54 \%$ of cases and renal failure associated with anuria in $46 \%$ of patients (Table-3).

The mean serum creatinine value at admission was $1025 \mu \mathrm{mol} / \mathrm{l}$ with extremes of 273 and 2065 $\mu \mathrm{mol} / \mathrm{l}$. According to the KDIGO (Kidney Disease Improving Global Outcome 2012) classification, the AKI was stage 2 and 3 in $7.9 \%$ and $92.1 \%$, respectively.

Out of 63 patients, $45(71 \%)$ came from the gynaecology and resuscitation departments of Point $G$ University Hospital. The others were referred by the gynecology departments of Gabriel Touré UHC (11.1\%), Kati UHC (4.8\%), the reference health centers (level 2) of Bamako (6.3\%) and regional hospitals $(6.3 \%)$.

Prenatal consultations were not made in $28.6 \%$ of cases (18 patients). Multiparous women were numerous $71.4 \%$ versus $28.6 \%$ of primiparous women (Table-4). The history of gestational hypertension and chronic hypertension was noted in 57.1 and $6.3 \%$ of cases. Caesarean section was performed in $60.3 \%$ of patients.

Clinically, vomiting, physical asthenia, and vertigo dominated the symptomatology of our patients in $88.9 \%, 79.4 \%$, and $60.3 \%$ of cases, respectively. This clinical symptomatology is mostly related to acute uremia, severe anemia and ension surges. On clinical examination, conjunctival pallor and jaundice were found in $95.6 \%$ and $19 \%$ of patients respectively.

Anuria, oliguria and retained diuresis were found in $49.2 \%, 36.5 \%$ and $14.3 \%$ of cases respectively. 
Blood pressure was normal in $30.1 \%$ of the cases compared to $69.8 \%$ with hypertension. WHO grade 2 hypertension was found in $36.5 \%$ of hypertensive patients followed by WHO grade 3 hypertension $(17.5 \%)$ and grade 1 hypertension $(15.9 \%)$. The mean blood pressure was $150.39 / 98.68$ $\mathrm{mmHg}$.

Severe anemia (hemoglobin level between 3 and $7 \mathrm{~g} / \mathrm{dl}$ ) was found in 35 patients (55.6\%), regenerative in $46.0 \%$ of cases. Hyperleukocytosis (predominantly polynuclear neutrophilic) and thrombocytopenia were found in $77.8 \%$ and $38.1 \%$ of cases respectively.

Concerning the haemolysis balance sheet, the search for schizocyte was positive in $42.9 \%$ of patients, collapsed plasma haptoglobin in $34.9 \%$, total bilirubin and LDH elevation in $47.6 \%$ and $58.7 \%$ of cases. One out of two patients had evidence of hepatic cytolysis (Table-5).

Thirty-one patients had a urinary tract infection (UTI) board. The germs found in the uroculture were in order of frequency Escherichia coli (19), Klebsiella pneumoniae (9) Acinetobacter baumannii (1), Enterobacter sp (1).

Among non-anuric women $(n=49)$, the search for proteinuria was minimal in $57.1 \%$ of patients, moderate and massive in $15.9 \%$ and $4.8 \%$ of cases. On ultrasound, kidney size was normal in $76.2 \%$ of patients.

The causes of AKI were severe preeclampsia $(55.5 \%)$, postpartum hemorrhage $(36.5 \%)$, postabortion sepsis $(3.2 \%)$, severe Palsmodium falciparum malaria $(1.6 \%)$, severe preeclampsia added (1.6\%), and hemolytic uremic syndrome $(1.6 \%)$ (Table-6).
The main visceral complications associated with Severe Preeclampsia were HELLP syndrome $(33.3 \%)$, PRH $(30.1 \%)$, and acute pulmonary edema (12.7\%) (Figure-1).

According to Sher's classification, RPH was grade II, IIIa, and IIIb in $10.5 \%, 26.3 \%$, and $63.2 \%$, respectively. There were no cases of acute fatty liver disease in pregnancy.

In terms of evolution 46 patients $(73 \%)$ were dialysed on the following criteria: anuria (58.6\%), hyperkalemia $(28.3 \%)$, acute pulmonary edema $(10.9 \%)$, and severe metabolic acidosis with hydrosodic retention $(2.2 \%)$.

Among dialysis patients, 31 patients normalized their renal function $(67.9 \%)$ versus 1 case of partial recovery (CKD stage 2), 4 patients progressed to end-stage renal disease, 7 cases of death were observed, and 3 cases of discontinuation of follow-up against medical advice.

For patients not on dialysis, recovery of adintegrum renal function (mean serum creatinine $84.50 \pm 12.59 \mu \mathrm{mol} / \mathrm{L}$ ) was observed in 16 patients and 1 case of death due to septic shock with multiviscular failure.

The causes of maternal deaths in dialysis patients were hyperkalemia (4 cases), acute pulmonary edema with respiratory distress (2 cases) and severe metabolic acidosis (1 case).

Perinatal mortality (stillbirths and deaths of newborns less than 1 week old) was $41.2 \%$.

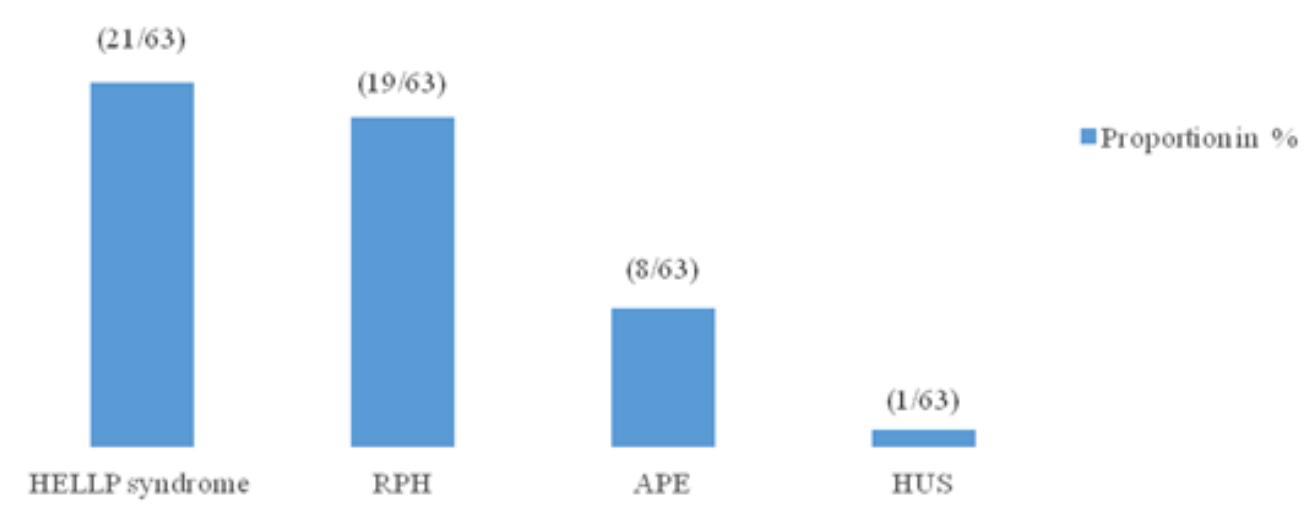

Fig- 1: Complications of preeclampsia 


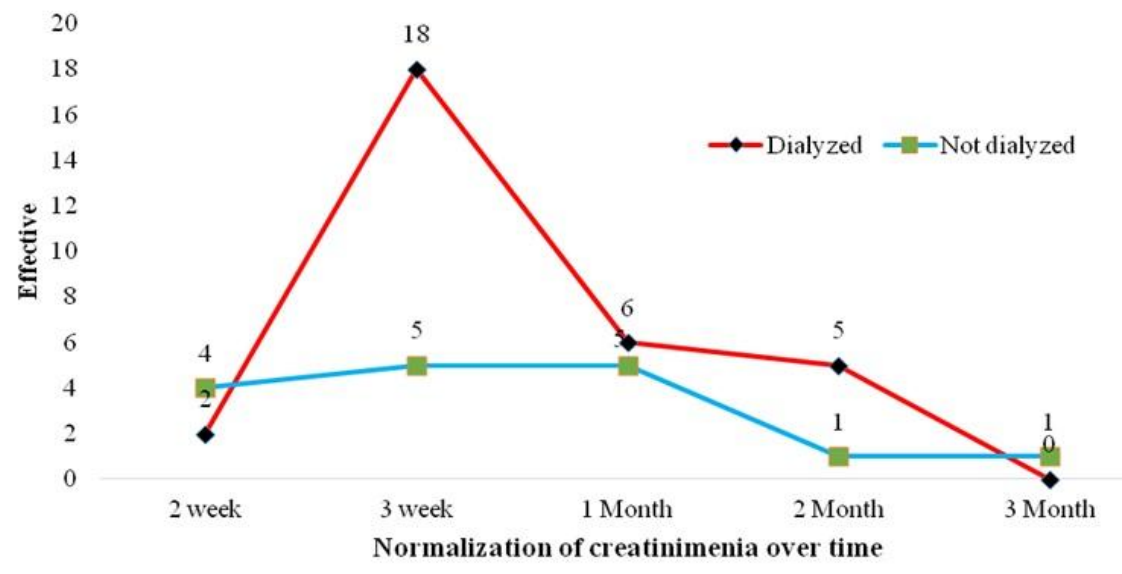

Fig-2: Trends in recovery of renal function according to hemodialysis management

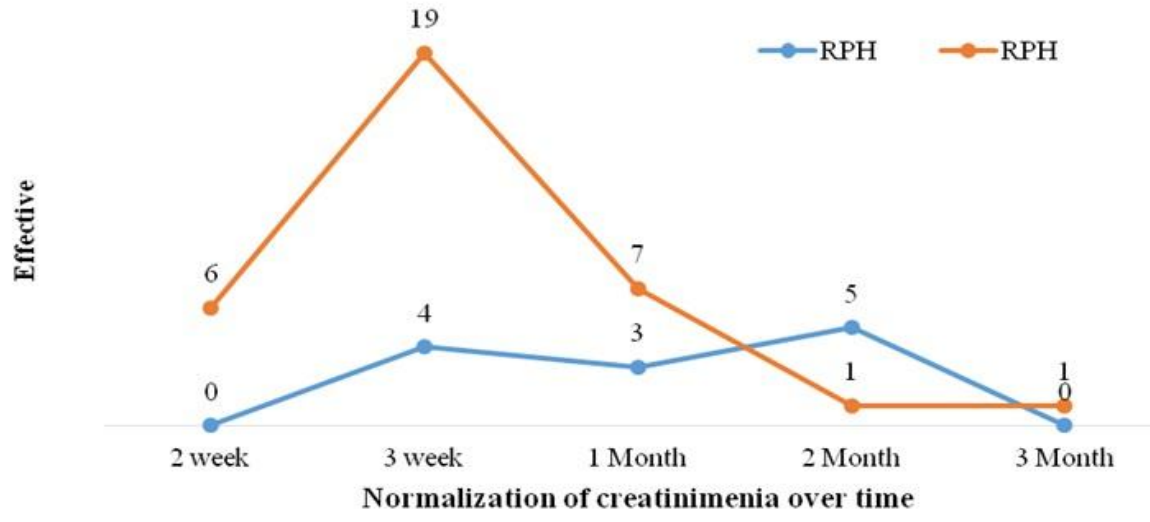

Fig-3: Relationship between RPH and time to normalization of renal function

$$
\text { Chi-square }=13,650 \quad \mathrm{ddl}=4 \quad \mathrm{p}=0,009
$$

Table-2: Age distribution of 63 women

\begin{tabular}{|l|c|c|}
\hline Age in year & Effective & Proportion in \% \\
\hline $16-20$ & 10 & 15,9 \\
\hline $21-25$ & 10 & 15,9 \\
\hline $26-30$ & 29 & 46,0 \\
\hline $31-35$ & 10 & 15,9 \\
\hline $36-40$ & 4 & 6,3 \\
\hline Total & 63 & 100,0 \\
\hline
\end{tabular}

Table-3: Distribution of 63 patients according to reasons for hospitalization

\begin{tabular}{|l|c|c|}
\hline Reasons for hospitalization & Effective & Proportion in \% \\
\hline Renal failure & 34 & 54,0 \\
\hline Renal failure + anuria & 29 & 46,0 \\
\hline Total & 63 & 100,0 \\
\hline
\end{tabular}

Table-4: Gynaecological-Obstetrical History

\begin{tabular}{|c|l|c|c|}
\hline Gyneco-obstetric history & & Effective & Proportion in \% \\
\hline Consultation prénatale & Oui & 45 & 71,4 \\
\hline & Non & 18 & 28,6 \\
\hline Parity & Multiparity & 45 & 71,4 \\
\hline & Primiparity & 18 & 28,6 \\
\hline
\end{tabular}


Table-5: Distribution of the 63 patients according to haemolysis and transaminase levels

\begin{tabular}{|l|c|c|}
\hline & & Effective (Percentage) \\
\hline Search for schizocyte & Positive & $27(42,9)$ \\
\hline & Negative & $36(57,1)$ \\
\hline Total bilirubin in mg/dl & High & $30(47,6)$ \\
\hline & Decrease & $33(52,4)$ \\
\hline & High & $37(58,7)$ \\
\hline Haptoglobin in g/l & Normal & $26(41,3)$ \\
\hline & High & $3(4,8)$ \\
\hline & Normal & $38(60,3)$ \\
\hline ASAT in IU/l & Decrease & $22(34,9)$ \\
\hline & High & $34(54,0)$ \\
\hline ALAT in IU/l & Normal & $29(46)$ \\
\hline & High & $30(47,6)$ \\
\hline & Normal & $33(54,2)$ \\
\hline
\end{tabular}

Table-6: Etiology of Obstetrical AKI

\begin{tabular}{|l|c|c|c|c|}
\hline Etiology & Severe preeclampsia & Haemorrhage & Sepsis & Others \\
\hline $\begin{array}{l}\text { Hachim } \\
\text { Maroc [13] }\end{array}$ & $74,5 \%$ & $7,2 \%$ & $11 \%$ & 7,1 \\
\hline $\begin{array}{l}\text { Rizwan } \\
\text { Pakistan [14] }\end{array}$ & $17,14 \%$ & $57,13 \%$ & $11,42 \%$ & $14,31 \%$ \\
\hline $\begin{array}{l}\text { Tounkara } \\
\text { Mali [7] } \\
\text { n=28 }\end{array}$ & $28,57 \%$ & $35,7 \%$ & $17,85 \%$ & 17,85 \\
\hline $\begin{array}{l}\text { Our Study } \\
\text { n=63 }\end{array}$ & $55,5 \%$ & $36,5 \%$ & $3,2 \%$ & $* 4,8 \%$ \\
\hline
\end{tabular}

*Others: severe Palsmodium falciparum malaria (1.6\%), severe preeclampsia added (1.6\%), and hemolytic uremic syndrome $(1.6 \%)$

Table-7: Progression of Obstetric ARI in Patients

\begin{tabular}{|l|c|c|l|l|l|}
\hline & Total recovery & Partial recovery & end-stage renal disease & Death & Abandonment \\
\hline Our study & $74,63 \%$ & $1,60 \%$ & $6,34 \%$ & $12,70 \%$ & $4,73 \%$ \\
\hline Tounkara AA [7] & $39,28 \%$ & $3,57 \%$ & $17,85 \%$ & $21,42 \%$ & $17,85 \%$ \\
\hline Rizwan N [19] & $53 \%$ & $7,02 \%$ & $14,27 \%$ & $25,7 \%$ & 0 \\
\hline
\end{tabular}

\section{DISCUSSION}

The hospital prevalence of obstetric AKI during the study period in the nephrology department of Point $G$ teaching hospital was $2.08 \%$. A study conducted in Mauritania over a period of 3 years reported a hospital prevalence of $4.61 \%$ [6]. Our low prevalence could be explained by the lower access of women to nephrology, especially those not residing in the district of Bamako. This is a hospital prevalence that could not be extrapolated to the general population.

Obstetrical renal failure is declining sharply in countries where abortion is legalized and prenatal consultations are mandatory [5].

The mean age of our patients was $27.31 \pm 5.49$ years, with extremes of 16 and 40 years. In 2012, Tounkara in the same department had found a mean age of 25.9 years and extremes of 17 and 42 years [7]. On the other hand, Lemrabott in Mauritania and Mahfoudh in Tunisia had respectively found an average age of 32 and 37.8 years $[6,9]$.
In sub-Saharan Africa in general, and in Mali in particular, women are married at a younger age. According to the Demographic and Health Survey in 2018 in Mali, by the age of 25 almost all women had already contracted a first union $(90 \%)$ [10].

Concerning the gynaecological-obstetrical history; the prenatal consultation was carried out by the patients in $71.4 \%$ of cases against $21.4 \%$ in the Tounkara study [7]. There were 18 primiparous women $(28.6 \%)$ with a mean parity of 3.91 and extremes of 1 and 11 parities. Gestational hypertension was observed in $38.1 \%$ of cases and chronic hypertension in $6.3 \%$ of cases.

ARF was gestational in only 2 patients and was diagnosed postpartum in all others. The 1 st case of gestational AKI at 31 weeks amenorrhea was secondary to severe malaria with Plasmodium falfciparum with a positive thick drop at 1100 trophozoites/field in a context of infectious syndrome in the absence of 
tension, bleeding and other factors that could explain the occurrence of AKI. The patient was 22 years old, residing in a village in the Ségou region (3rd region of Mali, a malaria endemic zone), and had not had antenatal consultations. The second case occurred at 24 weeks of amenorrhea in a 36-year-old patient in a context of severe pre-eclampsia.

The other causes were dominated by severe preeclampsia $(55.5 \%)$, postpartum hemorrhage $(36.5 \%)$, post clandestine abortion sepsis $(3.2 \%)$ and hemolytic uremic syndrome $(1.6 \%)$.

In the various published series, hemorrhage is often the main cause of organic ARI [11, 12]. Tounkara found haemorrhage and severe preeclampsia in $35.7 \%$ and $28.57 \%$ of cases [7].

The high frequency of severe preeclampsia in this study could be explained by the increase in the incidence of hypertension in the general population in sub-Saharan Africa in recent decades [13].

Hemolytic uremic syndrome (HUS) and thrombotic thrombocytopenic purpura (TTP) are rare; they can occur during pregnancy or in the immediate postpartum period. They are mimics of preeclampsia. An important distinction must be made with the frequent obstetric complications. The severity of renal manifestations and the absence of hepatic cytolysis may be more important in making the diagnosis [14].

We found 21 cases of HELLP syndrome versus 155 cases in a cohort by Adnani et al., [15]. The Hemolysis Elevated Liver enzyme, Low Platelets (HELLP) syndrome is a frequent complication of severe preeclampsia and is responsible for severe maternal and fetal morbidity and mortality [15]. In our series the other complications were RPH (30.1\%), acute pulmonary edema (12.7\%) and HUS (1.6\%).

HELLP syndrome, hemorrhage, bleeding disorders, hemolysis, and RPH are the other visceral complications observed during severe preeclampsia that are prognostic and risk factors for the development of ARF [11].

PRH and HELLP syndrome are common complications during preeclampsia. In a cohort of 155 cases of complicated preeclampsia with HELLP syndrome in the obstetric intensive care unit of the Casablanca University Hospital, Adnani et al., found 51 cases of ARF. She was accompanied by RPH in 35 parturients [15].

In this study, no cases of acute fatty liver steatosis in pregnancy were noted. This is a very rare event, manifested by profuse vomiting (due to a disorder of long-chain fatty acid metabolism), frank cholestatic jaundice, extensive hepatic cytolysis, and a bright liver appearance on ultrasound [16].

Haemodialysis was practised in $73 \%$ compared to $53.6 \%$ in the Tounkara study [7]. Nowadays, in our context, hemodialysis treatment is increasingly rapid in the case of ARF in view of emergency indications. The haemodialysis session lasted on average 2 hours 15 minutes, and was shorter for patients who were unstable or had visceral damage.

Among the hemodialysis patients, 31 of the patients progressively normalized their renal function $(67.9 \%)$ versus 1 case of partial recovery (stage 2 CKD).

Four patients progressed to end-stage chronic renal failure in whom renal biopsy could not be performed due to the lack of a technical platform and the low socio-economic level of the patients. These were obviously young primiparous patients with severe preeclampsia.

According to the results of the Kattah et al., study, preeclampsia during the first pregnancy is indeed associated with an increased risk of chronic renal failure (relative risk $\times 4$ ); this risk is even greater (relative risk $\times 10$ ) in the event of recurrence of preeclampsia [17]. Seven cases of death have been reported. 3 patients dropped out of follow-up against medical advice.

For patients not on dialysis, recovery of adintegrum renal function was observed in 16 patients and 1 case of death due to septic shock with multivisceral failure.

Generally speaking in terms of patient evolution (dialysis and non-dialysis patients included) this study shows a recovery rate of renal function of $74.63 \%$ and $6.34 \%$ of CKD cases, compared to $39.28 \%$ and $17.85 \%$ in the Tounkara study. This difference could be explained by a decrease in the frequency of abandonment of medical follow-up (Table VII).

Maternal mortality was $12.69 \%$. Tounkara had recovered $21.42 \%$. According to data from the literature the maternal mortality from obstetric ARI in developing countries often reaches $15 \%$ [5, 18]. Perinatal mortality (stillbirths and deaths of newborns less than one week old) was $41.2 \%$. The high frequency of HRP grade III could explain this rate. The mean time to normalization of renal function in general was $4 \pm 2$ weeks with extremes of 2 and 11 weeks. Dialysis patients recovered renal function in 3 weeks in $58 \%$ of cases (Figure-2). The vast majority of patients with $\mathrm{PRH}$ were on dialysis, i.e. 18 out of 19 patients $(\mathrm{p}=0.016)$. PRH was associated with delayed normalization of renal function $(\mathrm{p}=0.009)$ (Figure-3). 
The limitations of this study were the lack of a technical platform, i.e. the non-performance of kidney biopsy in the said structure and its high cost in private institutions. The search for immunological diseases was not systematized. The discharge of patients from hospital against medical advice and the abandonment of medical follow-up contributed to the reduction in size of this study, but also the absence of medical follow-up by some patients living in rural areas and the difficulties of access to specialized services. In order to remedy this, it is important to actively involve the general practitioners of level 1 health centres (community health centres) in the diagnosis and short-, medium- and long-term follow-up of cases of acute renal failure.

\section{CONCLUSION}

Obstetric ARF remains common in Africa. PE$\mathrm{E}$ is a common etiology. Screening for renal impairment during pregnancy should be routine. We insist on primary prevention of obstetrical complications, decentralization of dialysis centers, and close collaboration between nephrologist, obstetrician and resuscitation anesthesiologist in order to significantly reduce this significant morbi-mortality.

\section{Conflict of interest: None}

\section{REFERENCES}

1. Pertuiset N, Grunfeld JP. Acute renal failure in pregnancy. Bailliers Clin Obstet Gyn, 1994;8:33351.

2. Jebali H, Laifi M, Hassen M, Kheder R, Fatma LB, Rais L, Ben HF, Smaoui W, Krid M, Beji S, Zouaghi MK. Rein et grossesse. Néphrologie \& Thérapeutique. 2016 Sep 1;12(5):368-382.

3. Zelmat SA, Batouche DD, Sadaoui L, Kerboua KE, Chaffi B, Mazour F, Benatta NF. L'insuffisance rénale aiguë et grossesse: quels sont les facteurs prédictifs de sa survenue?. Néphrologie \& Thérapeutique. 2016 Sep 1;12(5):402-10.

4. Kanfer A, Kourilsky O, Peraldi MN, Combe C. Néphrologie et troubles hydroélectrolytiques. Paris : Masson, $3^{\text {rd }}$ édition, 2001.

5. Costa D B. L'insuffisance rénale aigue obstétricale : un problème de santé publique dans les pays en voie de développement. Néphrologie. 2001;22:3-4.

6. Lemrabott AT, Mah SM, Faye M, Saleck M, Cissé MM, Fall K, Diagne S, Mbengue M, Niang A, Diouf $\mathrm{B}, \mathrm{Ka} \mathrm{EH}$. Insuffisance rénale aiguë du post-partum en Mauritanie: prévalence, étiologies et facteurs pronostiques. Néphrologie \& Thérapeutique. 2017 Sep 1;13(5):365.

7. Tounkara AA. Problématique de la prise en charge de l'insuffisance rénale obstétricale dans le service de néphrologie du CHU du Point G. Batna J Med Sci. 2016;3: 429-432.

8. Khwaja A. KDIGO clinical practice guidelines for acute kidney injury. Nephron Clinical Practice. 2012;120(4):c179-84.

9. Mahfoudh O. Insuffisance rénale aiguë au cours de la grossesse et du post-partum. Néphrol \& Thér. 2018;14:335-402.

10. Enquête Démographique et de Santé au Mali 2018 (EDSM VI). Institut National de la Statistique (INSTAT), Cellule de Planification et Statistique Secteur Santé-Développement Social et Promotion de la Famille (CPS/SS-DS-PF) et ICF, 2019.

11. Naqvi R, Akhtar F, Ahmed E, Shaikh R, Ahmed Z, Naqvi A, Rizvi A. Acute renal failure of obstetrical origin during 1994 at one center. Renal failure. 1996 Jan 1;18(4):681-3.

12. Hachim K, Badahi K, Benghanem M. Insuffisance rénale aiguë obstétricale: L'expérience du Service de néphrologie, CHU Ibn Rochd, Casablanca. Néphrol. 2001; 22(1):29-31.

13. Yaméogo NV, Samadoulougou AK, Kagambèga LJ, Millogo GR, Yaméogo AA, Kologo KJ. Caractéristiques épidémio-cliniques de l'hypertension artérielle résistante du sujet noir africain. Ann Cardiol Angiol, 2014;8:26-32.

14. Miguil M, Salmi S, Moussaid I, Benyounes R. Insuffisance rénale aiguë hémodialysée en obstétrique. Néphrologie \& thérapeutique. 2011 Jun 1;7(3):178-81.

15. El Adnani I, Agzid N, Mahmal S, Hafiane Y, Mtioui N, Elkhayat S, Medkouri G, Benghanem M, Ramdani B, Moussaid I, Elyoussoufi S. Prévalence de l'insuffisance rénale aiguë dans le HELLP syndrome. Néphrologie \& Thérapeutique. 2016 Sep 1;12(5):368-9.

16. Ahmed KT, Almashhrawi AA, Rahman RN, Hammoud GM, Ibdah JA. Liver diseases in pregnancy: diseases unique to pregnancy. World Journal of Gastroenterology: WJG. 2013 Nov 21;19(43):7639-46.

17. Kattah AG, Asad R, Scantlebury DC, Bailey KR, Wiste HJ, Hunt SC, Mosley TH, Kardia SL, Turner ST, Garovic VD. Hypertension in pregnancy is a risk factor for microalbuminuria later in life. The Journal of Clinical Hypertension. 2013 Sep;15(9):617-23.

18. Belenfant X, Pallot JL, Reziz K, Saint Léger S. Insuffisance rénale aiguë et grossesse. EMCNéphrologie. 2004 May 1;1(2):44-54.

19. Rizwan N, Uddin SF. Obstetrical acute renal failure: a challenging medical complication. Journal of Ayub Medical College Abbottabad. 2011 Dec 1;23(4):66-8. 